\title{
СТРОЕНИЕ, ФУНКЦИИ И ОСОБЕННОСТИ НАКОПЛЕНИЯ ТЯЖЕЛЫХ МЕТАЛЛОВ И МИКРОЭЛЕМЕНТОВ В ВОЛОСЯНОМ ПОКРОВЕ ЛОСЕЙ РАЗНЫХ ВОЗРАСТНЫХ ГРУПП
}

\author{
V.F. Pozdnyakova, M.V. Stepanova, \\ E.A. Pivovarova, E.N. Olenchuk
}

\section{THE STRUCTURE, FUNCTIONS AND FEATURES OF ACCUMULATION OF HEAVY METALS AND MICROELEMENTS IN HAIRED COVER OF MOOSES OF DIFFERENT AGE GROUPS}

Позднякова В.Ф. - д-р с.-х. наук, проф., зав. каф. технологии производства и переработки сельскохозяйственной продукции Ярославской государственной сельскохозяйственной академии, г. Ярославль.

E-mail: vera-pozdnyakova@yandex.ru

Степанова М.B. - канд. биол. наук, доц. каф. ветеринарно-санитарной экспертизы Ярославской государственной сельскохозяйственной академии, г. Ярославль.

E-mail: stepanova-marina@bk.ru

Пивоварова E.A. - канд. С.-х. наук, доц. каф. зоотехнии Ярославской государственной сельскохозяйственной академии, г. Ярославль.

E-mail: e.nikolaeva@yarcx.ru

Оленчук Е.Н. - канд. ветеринар. наук, доц. кафр. внутренних незаразных болезней, хирургии и акушерства Костромской государственной сельскохозяйственной академии, Костромская обл., Костромской р-н, пос. Караваево.

E-mail: olen4uk.@yandex.ru

В условиях постоянного антропогенного загрязнения биосфреры особую значимость приобретает вопрос изучения возможности жизнедеятельности организмов в условиях среды техногенного загрязнения и поиска порога, вызывающего необратимые изменения биологических систем. Животные в ходе эволюции приобрели цельй комплекс компенсаторных реакций, которые позволяют им поддерживать постоянство внутренней среды в субтоксических условиях окружающей среды. Волосяной покров тела животного служит защитой организма от внешних воздействий, участвует в регулировании теплообмена и в восприятии различных раздражителей из окружающей среды. В статье приводятся ре-
Pozdnyakova V.F. - Dr. Agr. Sci, Prof., Head, Chair of Production Technology and Processing of Agricultural Production, Yaroslavl State Agricultural Academy, Yaroslavl.

E-mail: vera-pozdnyakova@yandekh.ru

Stepanova M.V. - Cand. Biol. Sci., Assoc. Prof., Chair of Veterinary and Sanitary Examination, Yaroslavl State Agricultural Academy, Yaroslavl.

E-mail: stepanova-marina@bk.ru

Pivovarova E.A. - Cand. Agr. Sci., Assoc. Prof., Chair of Zootechnics, Yaroslavl State Agricultural Academy, Yaroslavl.

E-mail: e.nikolaeva@yarcx.ru

Olenchuk E.N. - Cand. Veterinary Sci., Assoc. Prof., Chair of Internal Noncontagious Diseases, Surgery and Obstetrics, Kostroma State Agricultural Academy, Kostroma Region, Kostroma District, S. Karavaevo.

E-mail: olen4uk.@yandex.ru

зультаты исследования волосяного покрова лосей разных половых и возрастных групn, содержащихся в условиях государственного природного заказника «Сумароковский» Костромской области. В связи с приручением и одомашниванием лосей встает вопрос по всестороннему изучению строения, функций и особенностей накопления тяжелых металлов и микроэлементов в волосяном покрове лосей разных половых и возрастных групп. Отличительной чертой лосей является уникальное строение их волосяного покрова, которое помогает им жить в достаточно суровых условиях при низких температурах. Волосяной покров лосей состоит в основном из остевых волос, пуховые волосы более тонкие, встре- 
чаются редко и в основном на нижней части живота. Волосяной покров лося грубый, толстый, слегка волнистьй, достигает длины на холке в зимний период до 18 сантиметров. Линька проходит один раз в год. Микроскопические исследования показали, что чешуйки на поверхности ости располагаются очень плотно в виде черепищы или плиток. Микроэлементный анализ шерсти животных показал высокие кумулятивные способности биосубстрата, составлен ранжированный ряд элементов, установлены основные закономерности их накопления. Данные исследования дополняют теоретические знания по изучению волосяного покрова лосей и имеют практическое значение.

Ключевые слова: лось, волосяной покров, ость, пуховой волос, извитость, ювенильная линька, окраска волос, подшерсток, микроэлементы, тяжелье металлы, биосубстраты.

Under the conditions of constant anthropogenic pollution biosphere, the study of the possibility of vital activity of the organisms under the conditions of technogenic pollution and the search for a threshold causing irreversible changes in biological systems is of particular importance. During the evolution the animals acquired a whole complex of compensatory reactions allowing them to maintain a constant internal state in subtoxic environmental conditions. The hairline of the animal's body serves as the defense against external influences, participates in the regulation of heat transfer and in the perception of various irritants from the environment. The research presents the results of the study of the hairline of moose of different sex and age groups kept in the conditions of the Sumarokovsky State Natural Reserve of Kostroma Region. Due to taming and domestication of moose, the question arises of a comprehensive study of the structure, functions and characteristics of the accumulation of heavy metals and trace elements in the hairline of moose of different sex and age groups. A distinctive feature of moose is their unique hairline structure, helping them live in rather severe conditions at low temperatures. Moose hair consists mainly of core hair, downy hair is thinner, rare and mainly on the lower abdomen. The elk hair is coarse, thick, slightly wavy, reaches a length at the withers in winter of up to 18 centimeters. Shedding takes place once a year. Microscopic studies showed that the flakes on the surface of the spine are very densely in the form of a tile or tiles. Microelement analysis of animal hair showed high cumulative abilities of the biosubstrate, a ranked number of elements was compiled, and the basic patterns of their accumulation were established. These studies supplement theoretical knowledge on the study of elk hair and are of practical importance.

Keywords: moose, hairline, awn, downy hair, crimp, juvenile molting, hair coloring, undercoat, trace elements, heavy metals, biosubstrates.

Введение. В условиях постоянного антропогенного загрязнения биосферы особую значимость приобретает вопрос изучения возможности жизнедеятельности организмов в условиях среды техногенного загрязнения и поиска порога, вызывающего необратимые изменения биологических систем. Животные в ходе эволюции приобрели целый комплекс компенсаторных реакций, которые позволяют им поддерживать постоянство внутренней среды в субтоксических условиях окружающей среды.

Волосяной покров тела животного служит защитой организма от внешних воздействий, участвует в регулировании теплообмена и в восприятии различных раздражителей из окружающей среды. Он состоит из большого количества разнообразных волос, которые выполняют своеобразные фризиологические функции. В зависимости от времени года волосяной покров большинства животных находится в относительной стадии покоя, за исключением выпадения отдельных волос при выполнении груминга (чесание, чистка, облизывание). Во время линьки, которая может быть возрастной, сезонной или постоянной, происходит периодическая смена волосяного покрова. На теле животного, на разных его анатомических участках встречаются самые разнообразные по длине, толщине, форме и выполняемой функции волосы. Например, вибриссы (лат. vibrissae), располагаются на голове и выступают над поверхностью волосяного покрова около глаз, а также на верхней и нижней челюстях, выполняя функцию осязания [1].

Волосяной покров лося европейского (лат. Alces alces Linnaus) грубый, толстый, слегка волнистый. В зимний период на отдельных уча- 
стках тела он может достигать длины $10 \mathrm{~cm}$, а вдоль хребта он еще длиннее. Волосы на холке и сверху шеи достигают длины 16-18 см, особенно у самцов, образуют гриву и придают зверю специфическую горбатость. Губы лося покрыты короткими светлыми волосками. В нижней части ног волосы короткие, но особо прочные и упругие, что обусловлено вынужденными передвижениями по глубокому снегу, нередко с острой ледяной коркой в весенний период [1].

Окраска шерсти туловища, шеи, большей части головы и верха ног однотонная, буроваточерная или серовато-черная, а окраска конечностей светло-серая, почти белая. Оттенки окраски шерсти лося меняются по сезонам года, хотя линька бывает раз в год. В марте он теряет свой характерный блеск, в апреле у большинства лосей начинается выпадение старой шерсти, а в мае линька уже заканчивается сначала у самцов и яловых самок. В июне заканчивается линька у самок, которые отелились. Летом у всех лосей достаточно короткий волосяной покров, который сохраняется до сентября. В конце августа у лосей начинает отрастать зимний волосяной покров, появляется густой подшерсток. И к концу октября у большинства лосей тело уже покрыто густым зимним волосяным покровом. Лосята в первые четыре месяца своей жизни чаще всего имеют достаточно однородный рыжевато-бурый волосяной покров, иногда с темной полосой по хребту [2].

Особенности строения волосяного покрова животных имеют большое значение при адаптации к условиям низких температур, которая происходит за счет интенсивного роста волос, достигая генетически обусловленного максимального значения.

Ювенильная линька у лосят начинается в первых числах августа. Весь процесс линьки занимает около двух месяцев, причем наиболее упитанные лосята почти полностью заканчивают линьку раньше, уже к середине сентября. Линька начинается с седла и нижней поверхности тела, затем шея, голени и морда. Связь линьки и упитанности лосей представляет не только научный, но и практический интерес, поскольку ослабленное состояние животных должно учитываться при их содержании и транспортировке. По внешнему виду лосей, их волосяному покрову можно судить о возрасте, упитанности, здоровье и фризиологическом состоянии [1].

Взрослые лоси линяют раз в год, начиная этот процесс весной и заканчивая летом. К марту зимняя шерсть снашивается и теряет блеск. В первую очередь линяют голова и ноги, в последнюю - спина. Сначала проплешины покрываются очень короткими, почти черными волосами, которые по мере отрастания принимают буроватую или сероватую окраску. В началесередине лета все лоси имеют темную окраску и светлую, выцветшую - весной, перед началом линьки. Первыми заканчивают линьку самцы и яловые лосихи, последними - лосихи, имеющие лосят, а также больные или истощенные животные [3].

Структурной особенностью волосяного покрова лосей является то, что их волосы толще в середине, чем у основания. Это создает воздушную прослойку вокруг тела животного, которая выступает в качестве изолирующего слоя при согревании тела лося. Данный слой имеет большое значение для них, так как они обычно живут в холодном климате с глубоким снегом и холодными зимами. Температура тела лося 38$39{ }^{\circ} \mathrm{C}$, и этот изолирующий слой помогает регулировать теплообразование и теплоотдачу организма: удерживает тепло во время холодных месяцев и позволяет им жить комфортно в холодном климате, без риска переохлаждения, а также помогает оставаться на плаву во время купания. Это дает им возможность жить и фуннкционировать в более холодных условиях, которые они предпочитают. По сравнению с мясными породами крупного рогатого скота, который содержат на открытых площадках в зимний период, у лосей пуха содержится значительно меньше [1].

В последнее время активно ведутся работы по приручению и одомашниванию лосей и их практическому использованию. Лось является консументом первого порядка, занимает средний уровень трофической пирамиды, что наряду с относительно длинным периодом жизни обусловливает кумуляцию в его организме полютантов в количествах, способствующих более информативному анализу. Поскольку этот вид животных является охотничьим и его мясо употребляется в пищу человеком, то этот вид животных может использоваться в качестве индикато- 
ра природной среды. Также все актуальнее становится вопрос изучения физиологического баланса микроэлементного состава организма теплокровных животных, что является обязательным условием для обеспечения нормальной жизнедеятельности и поддержания здоровья. Общепризнанной является точка зрения о значительной роли в этом микроэлементов, в число которых входят и некоторые токсичные тяжелые металлы [4-6]. Загрязнение окружающей среды тяжелыми металлами и другими химическими веществами вызывает функциональные и органические изменения в организме животных и человека. При этом самым актуальным является изучение содержания микроэлементов в организме млекопитающих животных, прежде всего из-за их исключительных свойств накапливаться в организме и вызывать, даже в относительно малых дозах, нарушение иммунитета, неспецифрических фракторов защиты, а также фрункциональные нарушения и болезни $[6,7]$.

В последнее время в ряде регионов отмечается усиливающийся дисбаланс качественного и количественного содержания эссенциальных и токсичных микроэлементов в объектах окружающей среды (воздух, природная вода), депонирующих средах (снежный и почвенный покров), питьевой воде, растениях и др. [6, 8, 9]. В связи с этим встает вопрос по всестороннему изучению анатомических, биологических, фи- зиологических и кумулятивных особенностей этих животных [10].

Цель исследования. Изучить строение, функцию и особенности накопления тяжелых металлов и микроэлементов в волосяном покрове лосей разных половых и возрастных групп.

Задачи: изучить представленные образцы волос лосей по длине, массе волос на $1 \mathrm{~cm}^{2}$, количеству волос на $1 \mathrm{~cm}^{2}$, провести микроскопические и микроэлементные исследования разных категорий волос.

Материалы и методы исследования. Материалом для исследований послужили образцы волосяного покрова лосей разных половозрастных групп, взятые на середине последнего ребра в условиях государственного природного заказника «Сумароковский» Красносельского района Костромской области. Более $50 \%$ его территории покрыто лесом. Значительная часть лесных участков объединена в крупные лесные массивы, которые удалены от населенных пунктов и от сельскохозяйственных предприятий. В настоящее время значительная часть сельскохозяйственных угодий представлена залежами, зарастающими березой (Betula alba), осиной (Populous tremula L.) ольхой (Alder ordinaria) и сосной (Scottorum pinus), что является хорошей кормовой базой для лосей.

Характеристика животных, у которых были взяты образцы волос, представлена в таблице 1.

Характеристика лосей, у которых были взяты образцы волос

Таблица 1

\begin{tabular}{|c|c|c|c|}
\hline $\begin{array}{c}\text { Номер образца } \\
\text { волос }\end{array}$ & Кличка & Пол & Возраст \\
\hline 1 & Яхра & Самка & 1 год 7 месяцев \\
\hline 2 & Ромео & Самец & 2 года 7 месяцев \\
\hline 3 & Яфеза & Самка & 12 месяцев \\
\hline 4 & Ясония & Самка & 12 месяцев \\
\hline 5 & Ярвина & Самка & 12 месяцев \\
\hline
\end{tabular}

При этом определили метрическим методом длину волос (в см), массу волоса с $1 \mathrm{~cm}^{2}$ (мг), структуру и количество волос на $1 \mathrm{~cm}^{2}$. Микроскопическое исследование проводили с помощью метода «раздавленной капли» под объективом микроскопа с увеличением $\mathrm{x} 40$.
Отбор проб производили в соответствии с «Методическими рекомендациями по отбору проб...» [11]. Подготовку проб для определения содержания токсичных элементов (железо, медь, свинец, кадмий, мышьяк) проводили согласно ГОСТ 26929-94 «Сырье и продукты пи- 
щевые. Подготовка проб. Минерализация для определения содержания токсичных элементов». Исследования проводили в соответствии с ГОСТ 30178-96 «Сырье и пищевые продукты. Атомно-абсорбционный метод определения токсичных элементов», ГОСТ Р 51766-2001 «Сырье и продукты пищевые. Атомноабсорбционный метод определения мышьяка», ГОСТ 26930-86 «Сырье и продукты пищевые. Метод определения мышьяка», ГОСТ 307112001 «Продукты пищевые. Исследования по определению тяжелых металлов (железо, медь, кадмий, свинец, мышьяк) проводили на атомноабсорбционном спектрометре «КВАНТ-2АТ». Исследования были выполнены в условиях повторяемости и промежуточной прецизионности. При расчете концентраций определяемых элементов в пробах осуществлялась метрологическая обработка результатов в соответствии с ГОСТ Р ИСО 5725-6-2002 «Точность (правильность и прецизионность) методов и результатов измерений».

Во всех случаях проводилось от 2 до 5 проб. Каждая проба анализировалась в 3-4 повторностях. Для калибровки были использованы стандартные растворы металлов для железа, меди, кадмия, свинца, мышьяка. Ошибка (сигма) метода в целом не превышала $5 \%$.

Полученные данные обрабатывались статистически на персональном компьютере с использованием пакета STATISTICA, версия 6.0. Для проверки достоверности отличий между двумя выборками использовались критерии Стьюдента и Фишера, а между несколькими независимыми выборками по одному признаку однофакторный дисперсионный анализ и непараметрический дисперсионный анализ с применением критерия Краскала-Уоллиса. Для выяснения взаимозависимости между двумя и более выборками применялись регрессионный анализ и коэффрициент ранговой корреляции Спирмана. Для всех видов статистического анализа был принят уровень значимости 0,05.
Результаты и их обсуждение. Волосы лосей хорошо делятся на две категории - остевые и пуховые. У остевых волос тонкий корень и расширенный стержень, который постепенно сужается к верхушке и имеет едва заметную волнистость. У него хорошо развитый мозговой слой, который начинается в корне волоса в виде узкого прерывистого тяжа, где хорошо выражен периферический слой клеток, примыкающий к корковому слою. Данные клетки высотой до 56,76 мкм, преимущественно прямоугольной или овальной формы, поделены на сегменты, в центре, как правило, имеют ямку. Кутикулярные клетки в области корня практически не заметны на поверхности стержня, контуры их свободного края волнистые.

Резко выделяются по своему строению волосы на запястье, где у остевых волос корень постепенно и плавно переходит в стержень. Отчетливо видны границы мозгового и коркового слоев. Пуховые волосы более тонкие, встречаются редко, в основном на нижней части живота [12].

Исследованиями установлено, что волосяной покров лося состоит из разных по длине, грубых, толстых, ломких, слегка волнистых волос. У лосей встречаются остевые и пуховые волосы, но в наших образцах были найдены только остевые, что связано с местом их локализации. У остевых волос тонкий корень и расширенный стержень, который постепенно сужается к верхушке и имеет едва заметную волнистость. Длина волосяного покрова колеблется от 1,1 до 9,5 см, данные представлены в таблице 2. Анализируя полученные данные по длине волосяного покрова, установлено, что у взрослых особей (образцы № 1 и 2) общая максимальная длина больше на 1,45 см (16,2\%), общая средняя длина - на 1,51 см $(24,1 \%)$, общая минимальная длина - на 1,6 см (55,1\%), чем у лосят (образцы № 3-5).

Масса волос и их количество на $1 \mathrm{~cm}^{2}$ представлены в таблице 3. 


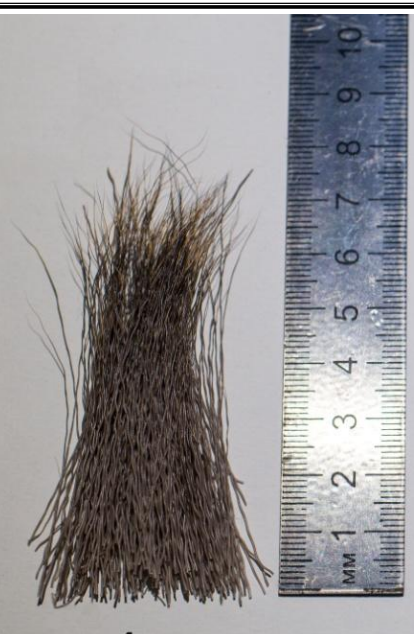

1

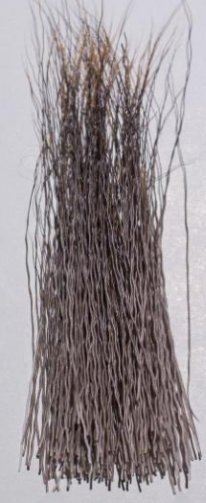

2

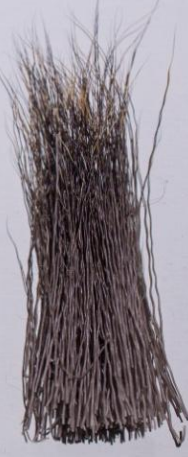

3

Рис. 1. Общий вид волос: 1 - самца по кличке Ромео; 2 - самки по кличке Яхра;

3 - самки по кличке Яфеза

Таблица 2

Длина волосяного покрова, см

\begin{tabular}{|l|c|c|c|c|c|}
\hline \multirow{2}{*}{ Длина волоса } & \multicolumn{5}{|c|}{ Номер образца } \\
\cline { 2 - 6 } & 1 & 2 & 3 & 4 & 5 \\
\hline Максимальная & 9,5 & 8,4 & 7,6 & 7,1 & 7,9 \\
\hline Минимальная & 3,5 & 2,3 & 1,1 & 1,6 & 1,2 \\
\hline Средняя & 6,5 & 5,35 & 4,35 & 4,35 & 4,55 \\
\hline
\end{tabular}

\section{Масса волос и их количество на 1 см²}

\begin{tabular}{|l|c|c|c|c|c|}
\hline \multirow{2}{*}{\multicolumn{1}{|c|}{ Показатель }} & \multicolumn{5}{c|}{ Номер образца } \\
\cline { 2 - 6 } & 1 & 2 & 3 & 4 & 5 \\
\hline Площадь сострига, см ${ }^{2}$ & 2,42 & 2,72 & 2,20 & 2,25 & 1,95 \\
\hline Масса волос, мг & 580 & 400 & 224 & 300 & 300 \\
\hline Масса волос на 1 см², мг & 240 & 147 & 101 & 133 & 154 \\
\hline Количество волос в образце & 634 & 624 & 736 & 865 & 710 \\
\hline Количество волос на 1 см & 262 & 229 & 328 & 384 & 364 \\
\hline Толщина волос, мкм & 370 & 420 & 280 & 274 & 280 \\
\hline
\end{tabular}

Анализ полученных данных показывает, что масса волос на $1 \mathrm{~cm}^{2}$ у взрослых животных (образцы № 1 и 2) на 68,2 мг (35,2 \%) больше, чем у лосят (образцы № 3-5). Количество волос на 1 $\mathrm{CM}^{2}$ у годовалых лосят (образцы № 3-5) превышает количество волос у взрослых животных на 128,2 (34,3 \%). Но волосы у них были тоньше и короче.

Особое внимание уделили микроскопическому строению волоса (рис. 2 и 3). Диаметр волоса колеблется в пределах от 200 до 400 и более мик- рометров, при разной толщине от корня до кончика. Мозговое вещество расположено в виде решетки и почти полностью заполняет волос. Узор чешуек - в виде черепицы или плиток и имеет масштаб примерно от 3 до 4 на 100 микрометров. Волосы лосей имеют показатель преломления по всей их длине около 1,56 и перпендикулярно к их длине около 1,55. Они имеют двойное лучепреломление около 0,01 и положительный знак удлинения. 


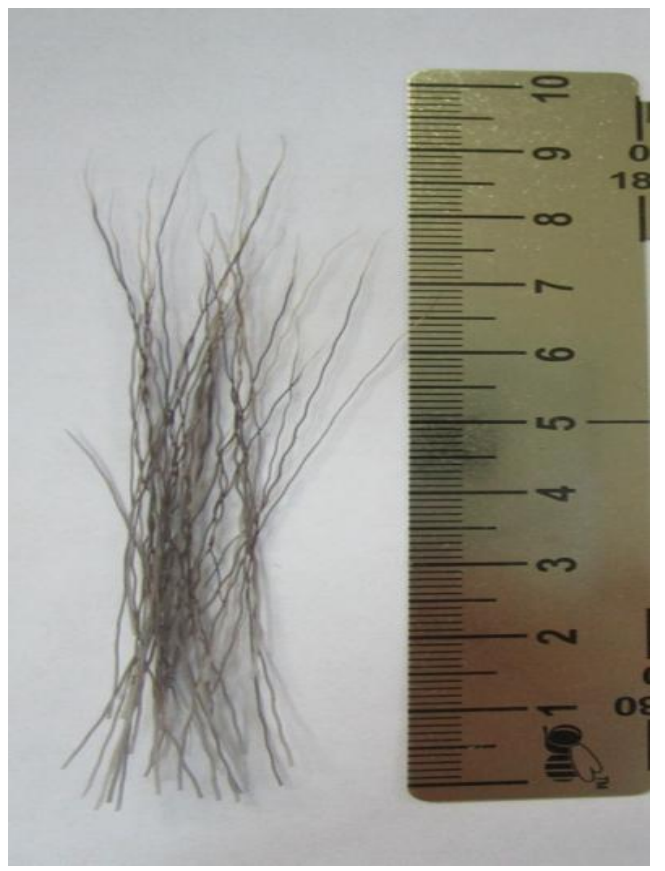

Pис. 2. Общий внешний вид волос

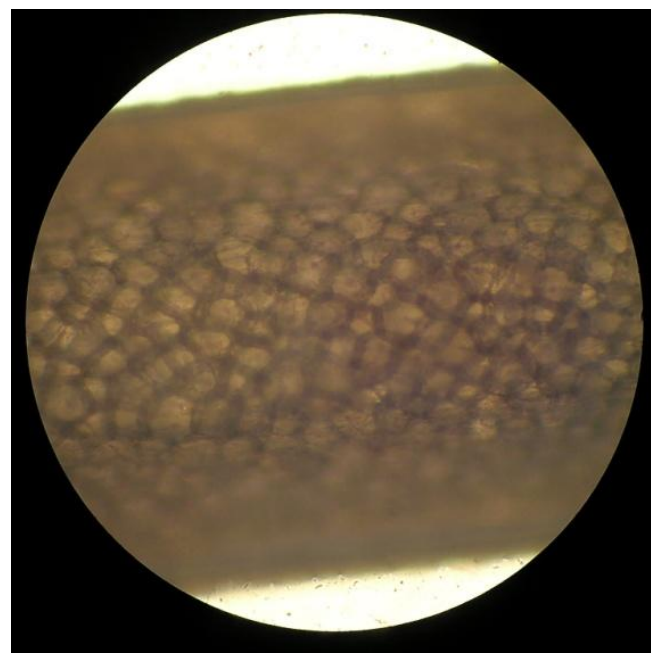

Puс. 3. Вид волоса под увеличением объектива микроскопа х 40

Благодаря тому, что середина имеет расширение, волосяной покров в целом создает воздушную прослойку, которая оберегает организм животного от перегревания, переохлаждения и помогает лосям держаться на плаву при переплывании водных препятствий. Мозаичное строение волоса обеспечивает жесткость покрова, что защищает животных от возможных повреждений, например от режущего края ледяного снега на сугробах. Хорошо выражен периферический слой клеток, преимущественно овальной формы, чешуйки кутикулы отчетливые, кольцевидной формы и их края округлые.
Шерсть давно используют в качестве альтернативного объекта анализа в клинической токсикологии и химии для диагностики отравлений тяжелыми металлами, патологии щитовидной железы и метаболических нарушений в организме [6]. Шерсть является легкодоступным биологическим материалом, простым и удобным для отбора. Пробы могут храниться длительный период времени и применяться для массовых скрининговых исследований [13].

Уровень содержания некоторых тяжелых металлов и микроэлементов (цинк, медь, кадмий, свинец, железо и мышьяк) представлен в таб- 
лице 4. Аккумуляцию металлов в шерсти лосей можно изобразить в виде ранжированного ряда: свинец < медь < железо < цинк в соотношении 1 : $2,9: 20,6: 56,3$.

Нормирования уровня исследуемых металлов и микроэлементов в шерсти лосей не существует. В исследуемых пробах не обнаружено кадмия и мышьяка, что, вероятно, связано с микроэлементным составом рациона, уровнем накопления некоторых микроэлементов и металлов (например, цинка, железа, меди, кальция и других), поступлением металла из окружающей среды и физиологическим состоянием животных [14].

Таблица 4

Содержание тяжелых металлов и микроэлементов (цинк, медь, кадмий, свинец, железо и мышьяк) в шерсти лося (M $\pm \mathrm{m})$, мг/кг сырого веса

\begin{tabular}{|c|c|c|c|c|c|c|}
\hline Биосубстрат & Цинк & Медь & Железо & Свинец & Кадмий & Мышьяк \\
\hline Волосы & $167,91 \pm 12,78$ & $8,64 \pm 0,21$ & $61,25 \pm 2,14$ & $2,98 \pm 0,13$ & 0 & 0 \\
\hline
\end{tabular}

В разных пробах биосубстратов отмечаются значительные колебания уровня накопления свинца, что зависит от дозы и продолжительности воздействия и может определяться отличиями в способности накапливать металл отдельными животными [5]. Он аккумулируется в организме даже при относительно низких уровнях содержания элемента в рационе и объектах окружающей среды [9]. Даже сублетальный уровень его накопления у животных может вызвать иммунологические, неврологические, биохимические и физиологические расстройства, способные влиять на иммунный ответ и воспроизводительную фуннкцию организма [15].

Уровень накопления меди в шерсти лосей составляет 8,64 $\pm 0,21 \mathrm{mг/кг} \mathrm{сырого} \mathrm{веса} \mathrm{живот-}$ ного и определяется поступлением из рациона, интерференцией меди с другими микроэлементами (железо, цинк и др.) и видом животного [8].

Цинк в шерсти животных содержится в концентрации 167,91士12,78 мг/кг сырого веса, что на $16,8 \%$ выше, чем в волосе крупного рогатого скота, где уровень накопления этого металла, в сравнении с тканями, наивысший. Его накопление определяется возрастом, полом, видом животных, концентрацией металла в окружающей среде и уровнем поступления с пищей [4].

Изменения обмена меди и цинка, отражаемые в элементном составе шерсти, однонаправлены. Процессы их обмена в организме довольно стабильны, но отмечается выраженная тенденция к повышению концентрации металлов в шерсти изучаемых лосей.

Железо в волосе лосей обнаружено в концентрациях меньших, чем цинк, что отмечается достаточно часто [4]. В шерсти животных выявлены корреляции между содержанием тяжелых металлов различной силы и направленности. Обнаружена высокая положительная связь между уровнем накопления меди и свинца $(\mathrm{r}=0,37$, при $p<0,05)$, что подтверждает исследования ряда авторов о синергическом эффректе накопления этих элементов [7].

Между уровнем накопления меди и цинка в шерсти лосей, а также свинца и железа обнаружены разнонаправленные ассоциации. Связь между цинком и медью была отрицательная $(r=$ $-0,31$, при $p<0,05)$, а между железом и свинцом - положительная ( $r=0,35$, при $p<0,05)$. Кадмий положительно коррелировал со свинцом, медью $(r=0,33$ и $r=0,33$ соответственно, при $p<0,05)$ и железом ( $r=0,37$, при $p<0,05)$. Выявлена обратная связь между содержанием цинка и свинца $(r=-0,35$, при $p<0,05)$. Эти данные согласуются с экспериментальными исследованиями, которые подтвердили повышенную экскрецию цинка при воздействии повышенных концентраций свинца, а цинковый дефицит усиливает поглощение свинца [16].

Заключение. На основании проведенных исследований установлено, что волосяной покров лосей на $90 \%$ состоит из остевых волос. Их строение в значительной степени отличается от строения волосяного покрова других животных. Мозаичное строение волоса обеспечивает им повышенную устойчивость к неблагоприятным факторам окружающей среды, а также помогает преодолевать водные препятствия и избегать травм при передвижениях по глубокому снегу. Микроэлементный анализ шерсти животных по- 
казал высокие кумулятивные способности биосубстрата, составлен ранжированный ряд элементов, установлены основные закономерности их накопления.

\section{Литература}

1. Позднякова В.Ф., Куклина Т.С., Поздняков И.А. Морфологическое строение волосяного покрова коров лимузинской породы при содержании на открытых площадках в зимний и летний периоды // Вестник Костромского государственного университета им. Н.А. Некрасова. - 2014. - Т. 20. - № 3. C. 40-42.

2. Соколов Н.В. Теоретические составляющие одомашнивания лося европейского. - Кострома: Авантитул, 2012. - 120 с.

3. Гриб Н.В., Голубева Н.Г., Фомичева Е.Д. Молочное лосеводство как перспективное направление зоокультуры лося // Тез. докл. Первого всесоюз. совещания по проблемам зоокультуры. - М., 1986. - Ч. 1.

4. Abdel-Mageed A.B., Oehme F.W. A review of the biochemical roles, toxicity and interactions of zinc, copper and iron: I. Zinc // Veterinary and Human Toxicology. - 1990. - Vol. 32, № 1. - P. 34-39.

5. ATSDR (Agency for Toxic Substances and Disease Registry). Toxicological profile for lead. - Atlanta: U.S. Department of Health and Human Services, Public Health Service, 2007. - 528 p.

6. Park S.B., Choi S.W., Nam A.Y. Hair trace elements in patients with goiter // Klin. Lab. Diagn. - 2006. - Vol. 8. - P. 19-21

7. Influence of copper status on the accumulation of toxic and essential metals in cattle /I. Blanco-Penedo [et al.] // Environment International. - 2006. - Vol. 32, № 7. - P. 901-906.

8. Environmental Dynamics and Human Exposure to Copper. Vol. 1. Environmental Dynamics and Human Exposure Issues / P.G. Georgopoulos [et al.]. - New York: International Copper Association, 2002.

9. Lead poisoning in cattle-transfer of lead to milk / A. Oskarsso [et al.] // Science of the Total Environment. - 1992. - Vol. 111, № 2-3. P. 83-94.

10. Позднякова В.Ф., Соколов Н.В. Адаптация лося европейского (Alces alces L.) к антро- погенным фракторам // Международный научно-исследовательский журнал. - 2015. № 9-3 (40). - С. 107-109.

11. Методические указания по отбору проб пищевой продукции животного и растительного происхождения, кормов, кормовых добавок с целью лабораторного контроля их качества безопасности. - М., 2009.

12. Джурович В.М., Соколов Н.В., Смирнов Л.Г. Лосеводство: учеб. пособие для вузов / под общ. ред. А.В. Баранова. - Кострома: Издво КГСХА, 2005. - $105 \mathrm{C}$.

13. Информативность биосубстратов при оценке элементного статуса сельскохозяйственных животных (обзор) / A.В. Харламов [и др.] // Вестник мясного скотоводства. 2014. - № 4 (87). - С. 53-58.

14. Nwude D.O., Babayemi J.O., Abhulimen I.O. Metal quantification in cattle: A case of cattle at slaughter at Ota Abattoir, Nigeria // Journal of Toxicology and Environmental Health Sciences. - 2011. - Vol. 3(9). - P. 271-274.

15. NRC (National Research Council). Mineral Tolerance of Domestic Animals. - Washington: National Academy of Press, 2005. $510 \mathrm{p}$.

16. Indicator ability of biosubstances in monitoring the moderate occupational exposure to toxic metals / A.R. Grabeklis [et al.] // Journal of Trace Elements in Medicine and Biology. 2011. - Vol. 25. - P. 41-44.

\section{Literatura}

1. Pozdnjakova V.F., Kuklina T.S., Pozdnjakov I.A. Morfologicheskoe stroenie volosjanogo pokrova korov limuzinskoj porody pri soderzhanii na otkrytyh ploshhadkah v zimnij i letnij periody // Vestnik Kostromskogo gosudarstvennogo universiteta im. N.A. Nekrasova. - 2014. - T. 20. - № 3. - S. 40-42.

2. Sokolov N.V. Teoreticheskie sostavljajushhie odomashnivanija losja evropejskogo. - Kostroma: Avantitul, 2012. - $120 \mathrm{~s}$.

3. Grib N.V., Golubeva N.G., Fomicheva E.D. Molochnoe losevodstvo kak perspektivnoe napravlenie zookultury losja // Tez. dokl. Pervogo vsesojuz. soveshhanija po problemam zookul'tury. - M., 1986. - Ch. 1. 
4. Abdel-Mageed A.B., Oehme F.W. A review of the biochemical roles, toxicity and interactions of zinc, copper and iron: I. Zinc // Veterinary and Human Toxicology. - 1990. - Vol. 32, № 1. - P. 34-39.

5. ATSDR (Agency for Toxic Substances and Disease Registry). Toxicological profile for lead. - Atlanta: U.S. Department of Health and Human Services, Public Health Service, 2007. - $528 \mathrm{p}$.

6. Park S.B., Choi S.W., Nam A.Y. Hair trace elements in patients with goiter // Klin. Lab. Diagn. - 2006. - Vol. 8. - P. 19-21

7. Influence of copper status on the accumulation of toxic and essential metals in cattle / I. Blanco-Penedo [et al.] // Environment International. - 2006. - Vol. 32, № 7. - P. 901-906.

8. Environmental Dynamics and Human Exposure to Copper. Vol. 1. Environmental Dynamics and Human Exposure Issues I P.G. Georgopoulos [et al.]. - New York: International Copper Association, 2002.

9. Lead poisoning in cattle-transfer of lead to milk / A. Oskarsso [et al.] // Science of the Total Environment. - 1992. - Vol. 111, № 2-3. P. 83-94.

10. Pozdnjakova V.F., Sokolov N.V. Adaptacija losja evropejskogo (Alces alces L.) $k$ antropogennym faktoram // Mezhdunarodnyj nauchno-issledovatel'skij zhurnal. - 2015. № 9-3 (40). - S. 107-109.

11. Metodicheskie ukazanija po otboru prob pishhevoj produkcii zhivotnogo i rastitel'nogo proishozhdenija, kormov, kormovyh dobavok s cel'ju laboratornogo kontrolja in kachestva bezopasnosti. - M., 2009.

12. Dzhurovich V.M., Sokolov N.V., Smirnov L.G. Losevodstvo: ucheb. posobie dlja vuzov / pod obshh. red. A.V. Baranova. - Kostroma: Izd-vo KGSHA, 2005. - $105 \mathrm{~s}$.

13. Informativnost' biosubstratov pri ocenke jelementnogo statusa sel'skohozjajstvennyh zhivotnyh (obzor) / A.V. Harlamov [i dr.] // Vestnik mjasnogo skotovodstva. - 2014. № 4 (87). - S. 53-58.

14. Nwude D.O., Babayemi J.O., Abhulimen I.O. Metal quantification in cattle: A case of cattle at slaughter at Ota Abattoir, Nigeria // Journal of Toxicology and Environmental Health Sciences. - 2011. - Vol. 3(9). - P. 271-274.

15. NRC (National Research Council). Mineral Tolerance of Domestic Animals. - Washington: National Academy of Press, 2005. $510 \mathrm{p}$.

16. Indicator ability of biosubstances in monitoring the moderate occupational exposure to toxic metals / A.R. Grabeklis [et al.] // Journal of Trace Elements in Medicine and Biology. 2011. - Vol. 25. - P. 41-44. 